\title{
Something for everyone Differentiated instruction in information studies
}

$\mathbf{F}$ or the first time this past spring, I taught a three-credit course called Information Studies in the Digital Age that our library has been offering for 11 years. The 200-level survey course covers information literacy topics in a technological context and combines theory and practice, for example tying together a discussion of Web 2.0 with actual website design. The course attracts undergraduate students majoring in disciplines as diverse as interactive media studies (IMS), strategic communications, sports management, and business.

Given the broad range of students enrolled and content covered, I set a formal teaching goal to provide differentiated instruction (DI), a form of instruction that works against the idea that one size fits all when it comes to learning. For the instructor, DI means getting to know individual students, addressing students' different learning styles, and building on their knowledge, skill sets, and interests.

For guidance on DI in a technological setting, I adapted information from Amy Benjamin's book called Differentiated Instruction Using Technology: A Guide for Middle and High School Teachers. ${ }^{1}$ With my energies directed towards designing the course from the ground up, I necessarily took a broad, rather basic view of DI, where students have freedom to personalize their learning activities and assignments. ${ }^{2}$ The technology-based character of the class provided something for students whether they were visual, audio, or kinesthetic learners and supported many opportunities for students to individualize their work. For instance, in creating podcasts, blogs, websites, and videos, they were able to make choices on their topics, formats, and multimedia tools used.

My students are members of Gen Z, whose use of computers for entertainment, communication, and seeking information is second nature. Considering this fact, I set out to integrate technology into the course as much as possible and approached computers as "environments for communication and learning" rather than static tools. ${ }^{3}$ While the course was designed to build students' computer skill sets, I also embedded technology in such a way that would support their critical thinking and creativity.

For example, blogging has become a customary part of college coursework as it provides an online forum for students to articulate and share ideas. I introduced blogging as a component of the course not only to capitalize on the free web-based tool WordPress, but also to generate discussion among students beyond the classroom. Students would blog about technology based on articles they read in current newspapers and periodicals by summarizing the article and providing commentary. Then, they would read their peers' blogs and comment. This ongoing assignment demonstrated DI because

Kate Lucey is education librarian at Miami University in Oxford, Ohio, email: luceyka@miamioh.edu

๑) 2015 Kate Lucey 
students were able to write about their own chosen topics; grading criteria was based on clarity of expression, thoroughness, and thoughtful opinions.

Benjamin also notes that DI classrooms are social and dynamic environments that support collaboration. ${ }^{4}$ I set up five groups early in the semester based on diversity of majors, graduating year, and skill sets. Throughout the semester, these groups worked on inclass activities that culminated in an advanced video project, where students created threeminute videos on a technology-related topic. I watched as groups bonded over the course of the semester, so that by the time the final video project rolled around, they were functioning as efficient teams.

When it came time to evaluate my performance and the course in general, I relied upon the feedback from my peer evaluators as well as the students. The feedback points towards introducing more DI methods for future iterations of the course. While my peer evaluators commended my class preparation and organization, they also encouraged me to think about moving off-script during class. I anticipate that this method of "teaching organically" as Benjamin calls it will become more comfortable as I teach more and gain more familiarity with the content and technology. One method that Benjamin suggests for promoting student inquiry is to use open-ended questions. ${ }^{5}$ Just as I tested for knowledge of the readings, I could elicit more in-depth written responses by routinely pitching more complex questions.

The students' anonymous course evaluations also indicate the opportunity for increasing DI. The course scored high marks for promoting analytical skills and encouraging topic appreciation. On the other hand, several students also indicated that they did not feel "challenged to think." Given that this is a general survey course attracting first years through seniors, this comment was a bit disappointing, but not really surprising. Still, there must be ways to reach those students in search of more academic challenges. Is there a way to offer DI that is flexible enough to accommodate seniors majoring in IMS, as well as first-year business majors?

My first course of action is to learn more about the IMS curriculum and other courses leading up to and following the 200-level course I teach. Second, I would like to broaden the scope of technology tools that students can draw upon-this plan stemming from my own increasing knowledge of such tools. Third, I will look for ways to insert more metacognitive activities, where students reflect upon the learning process itself. ${ }^{6}$

Benjamin admits, "Differentiated instruction is a lot of work, as is finding resources on the Internet and setting up a classroom Web site." I certainly can't argue with her as I anticipate spending nearly as much time and effort refining the course as I did in the initial set-up. With that said, I happily witnessed my hard work pay off in the form of student engagement with the course content. Of course, I derived the most enjoyment through getting to know the students. As a framework for the instructor, DI provides a way to discover and develop students' styles and interests.

\section{Notes}

1. Amy Benjamin, "Foundations," in Differentiated Instruction Using Technology: A Guide For Middle and High School Teachers (Larchmont, NY: Eye on Education), 1-12.

2. Ibid., 7

3. Ibid., 4.

4. Ibid., 2.

5. Ibid., 7.

6. Ibid.

7. Ibid., 5. n

\section{C\&RL News RSS}

Cover art, article links, and other valuable information from CERL News is available by subscribing to our RSS feed.

Point your Web browser to feeds. feedburner.com/candrlnews, and add our feed to your favorite feed reader. 